Abstract In this article I examine representations of sadomasochism in visual culture. Increasingly sadomasochistic imagery is becoming prominent and widespread in popular culture. I will ask which forms of sadomasochism are permitted and which are excluded or marginalized. The changing media regimes of visual representation will be addressed, arguing that cyberspace may provide a public forum for sadomasochists to challenge dominant stereotypical representations. Finally I will examine the impact of the current UK legislation to prosecute the viewers of 'extreme' pornographic material. This legislation reveals that certain intimate images are still denied the right to exist in visual culture.

Keywords citizenship, cyberspace, internet, pornography, sadomasochism

\title{
Perverting Visual Pleasure: Representing Sadomasochism
}

Has the sexualization of popular culture in late modern western societies truly led to a 'democratization of desire'? (McNair, 2002) Although we are undoubtedly living in an increasingly 'sexed up' culture, there remain clear limitations in terms of the forms of sexualization that are produced and consumed (Attwood, 2006). Instead of simply accepting the fact that things are getting more sexualized, we must question whose view of sexuality is dominant and whose is marginalized. Are certain types of sexuality given prominence in popular culture while others are excluded?

In 1984 Gayle Rubin noted that sadomasochists constitute a 'despised sexual caste' (Rubin, 1992: 279). Has the sexualization of culture changed this position? The representation of minoritized sexual groups is an important area of study as these images undoubtedly have an influence on shaping popular attitudes towards alternative sexualities; for many people the only encounters they have with a sexuality such as sadomasochism is through the media and popular culture. In this article I aim to look at the

Sexualities http://sex.sagepub.com Copyright @ 2009 SAGE Publications (London, Thousand Oaks, CA, New Delhi, Singapore and Washington DC) Vol I2(2): I8I-198 DOI: $10.1177 / 1363460708100918$ 
increasing number of mainstream images of sadomasochism (abbreviated to 'SM' hereafter), asking if this has led to SM practices being more widely tolerated in society. This is not, of course, to claim that images of SM in the media are a distinctly new phenomenon; Falk and Weinberg noted the existence of such representations back in 1983, and they clearly stretch far back beyond that. However, SM images were not as widespread as they are today. Since the 1990s we have seen a proliferation of SM images in western cultures, leading some to claim that 'representations of BDSM are everywhere' (Weiss, 2006: 111).

While this is something of an overstatement, the increase in images may mean that that SM is no longer the 'last taboo' (Weinberg and Magill, 1995). Nowadays there are television documentaries devoted entirely to the topic of SM, advertising campaigns use themes from SM culture (Pot Noodle, Ikea), pop music acts such as Madonna and Kylie have used SM imagery in videos and stage shows, and number of films cover SM and fetish topics (Kinky Boots, Pulp Fiction, Secretary). A 2006 poll by a DVD company even voted the spanking scene in Secretary as the 'sexiest film scene ever'. Likewise, SM paraphernalia has permeated mainstream culture and is visible in high fashion through 'SM chic' and on our high streets through shops such as Ann Summers. Some artefacts of SM have become mainstream and publicly visible. As Langdridge and Butt (2004) highlight, SM is becoming an increasingly popular and public sexual story.

However, we must ask what this 'mainstreaming' of SM really means (Taylor and Ussher, 2001). Does it necessarily signify that SM has become more accepted in society? Rather than simply equate the increased occurrence of these images with increased acceptance, we should instead attempt to put these images into context. We should ask what form of SM is being portrayed and for what purposes. What existing narratives are these images framed within? Do these images challenge the sexual status quo, or do they reinforce SM's otherness (or can they said to do both simultaneously)? I will argue that certain forms of SM have entered into the public consciousness but only on limited conditions.

In this article I begin with a look at some of the increasing number of popular-cultural representations of SM in the UK, giving a brief overview of what I feel are two of the dominant but seemingly contradictory positions that these images evoke - eroticization and pathologization. For the main part of the article I address the lack of control over public representation that minoritized sexualities face. I focus on the changing media regimes of visual representation, arguing that cyberspace may provide a public forum for sadomasochists to challenge dominant stereotypical representations. In the concluding sections I focus on the current UK legislation to prosecute the viewers of 'extreme' pornographic material. Despite the supposed increased public acceptance of 'mild' forms of SM, 
simultaneously some 'extreme' representations of SM are forced into invisibility through censorship.

\section{Pornonormative pathology?}

In this section I give a brief overview of the current media representations of SM. It is not within my scope to give an exhaustive account of all these representations; however, I shall briefly address a few specific examples that I feel highlight the two main narratives used to represent SM - pornonormativity ${ }^{2}$ and pathology. Obviously, trying to interpret from an image the motivations behind its production and dissemination, is a difficult (if not impossible) task. Likewise, trying to understand how images will be interpreted and used by viewers proves even more of a challenge. I am not wishing to claim that my readings of these visual texts are all encompassing, and I do not deny the fact that other readers may interpret these texts in different ways, including ways oppositional to the supposed dominant narrative (Hall, 1980). What follows, then, is my analysis of these images; my hope is that these initial readings and discussions provoke a wider debate about the implications of these representations. ${ }^{3}$

One area in which there has been a large increase in SM images is advertising. For example, a recent Mini campaign featured an interactive internet video of a PVC clad dominatrix who whips and paddles the car. ${ }^{4}$ Users are invited to 'whip around the site', and are told to 'click as hard as you like'. The advert is filled with innuendo that plays on SM - the braking system is said to 'prevent whiplash . . . but not the good kind of whiplash'. An example of SM in the mainstream? Yes. An example of SM becoming mainstream? No. The very fact that advertisers are using SM imagery in an advertising campaign instead highlights that it is still seen as a 'deviant' and 'naughty' pastime. This approach to advertising only 'works' because SM is still a taboo; it is what makes it a controversial campaign. The advert is supposedly produced with a male audience in mind, and proffers a predictable male heterosexual fantasy - a conventionally attractive female (alongside a conventionally good-looking car). Despite the woman holding the whip it could be argued that the man holding the mouse may ultimately be the one in control. ${ }^{5}$ For example, a quick glance at a motoring web forum discussing the advert finds a number of thrilled men praising its merits, although one despondently asks 'How come I can't click on her zipper?'. The figure of the female dominatrix is used in a multitude of other advertising campaigns, and not just for consumer goods. Both Keep Britain Tidy ${ }^{6}$ and Friends of the Earth have used SM imagery for campaigning ads. What are the political implications of adverts such as these? It would be farfetched to assume that these adverts will instantly lead people to accept or adopt SM practices. 
This pornonormative depiction is also seen in late night television 'documentaries' such as Fetish Seen and Dominatrix Reloaded. Programmes like these are usually found on low-budget UK broadcasters, for instance Channel 5 or cable channels. These shows are usually broadcast at 11 p.m., a time slot traditionally associated with post-pub viewing. Like the advertising campaigns, these programmes often contain pornonormative depictions of women; men are very rarely the focus of the camera gaze. An interest in these programmes is no longer marked as something deviant; they have become 'normal' television viewing for a particular audience segment (typified in Men o Motors' lad mag aesthetic as young, heterosexual, male). Therefore, these mainstream images could be read not as a sign of the acceptance of SM culture, but as part of a wider picture of an increasingly kinky, mainstream, heteronormative porn market. As Shortes (1998: 77) states:

Mainstream pornography producers have jumped onto the S/M-chic bandwagon with great enthusiasm. Beginning in about 1994, a look through the pages of Adult Video News would reveal that every other video box cover features $\mathrm{S} / \mathrm{M}$ accoutrements latex, leather, riding crops, gas masks, fetish shoes, and collars.

However, the increasingly kinky nature of the mainstream porn industry is not something that should be instantaneously overlooked. The way SM has moved from the dungeons into our living rooms, even on these limited terms, is still a cause for small celebration. The fact that mild SM now forms a 'normal' part of popular culture is a substantial change to note.

Moreover, the increase in SM imagery is not solely targeted at men; other media representations of SM are aimed at a female audience. For example, some mainstream women's magazines suggest experimenting with bondage and discipline to spice up one's sex life (Beckmann, 2001). SM is visible on UK high streets through shops such as Ann Summers, which has stores located in almost every mid-sized British city, and has arguably 'mainstreamed' the sex shop (Storr, 2003). In the context of the degendering of exposure to SM imagery, it is interesting to note that the most common media representation of SM remains female domination and male submission. Take for example an advert campaign by Voodoo Hosiery, which depicts a woman walking two naked men on a leash. The advert received many complaints, however the advertising standards board did not feel that the advert was sexist or degrading, arguing that it merely 'represented a satirical comment on a patriarchal world'. ${ }^{7}$ However, although gender roles may have been reversed (or parodied), are they really challenged? Despite representations of female supremacy, does hegemonic masculinity remain very firmly in control? 
It would be easy to instantly dismiss this mass-market concept of sexually dominant women as a cheap play on feminist values, with SM portrayed as a way for women to add variety to a tired heteromonogamous vanilla sex life, rather than offering an alternative. Yet the very suggestion that dominance and submission may form part of our sexual imaginaries is surely a better position to be in now than previous attempts to deny such fantasies and practices? So although ultimately there is no escaping the fact that SM has been made 'safe', toned down and commodified, we must ask if this is a worse situation than a time when mainstream portrayals of SM were unthinkable? Have some of the more productive or transgressive aspects of SM being transferred to these mainstream representations, or are these images always subject to underlying heteropatriarchal codes?

Yet this pornonormative depiction of SM is only one aspect of the story. The other side to SM, depicted in late-night documentaries and media exposés, is a dark and seedy underworld, the 'twilight world of the sadomasochist' (Binnie, 1994). These representations usually feature a male-female couple, usually suburban, to whom, presumably, we are not meant to feel sexually attracted (especially in contrast to the preceding model-like dominatrix), and also routinely feature unglamorized, 'seedy' locations such as sex clubs and swingers' parties. Programmes such as these tend to oscillate between these two contrasting presentations of SM: titillating voyeurism or 'freak show'. Yet the thing that unites these two forms of representation is comedy. They domesticate SM through humour - though arguably laughing at rather than laughing with their subjects. This connects these shows to a peculiarly British attitude to sex and representation, which contains it by making it a joke: saucy seaside postcards, the 'sex comedy' genre, Benny Hill, Carry On, and so on (Hunt, 1998). Again, however, this 'humorous' use of SM imagery is ambivalent: critics may argue that these portrayals both 'tame' and mock SM, making it the object of fun. Yet the greater visibility of SM in comedic texts could also be read as potentially empowering - how else could SM images appear on prime-time $\mathrm{TV} ?^{8}$

It is worthy of note, too, that the 11 p.m. time slot also broadcasts programmes about other marginalized sexual cultures, such as swingers, porn stars and transvestites. Sadomasochists and other sexual 'deviants' are often thrown together into one large group of sexual outcasts. Take, for example, the blurb for 2005 ITV2 show Unlikely Lovers:

Series telling tales of love found in the most unlikely of places and by the most unlikely of people. Featuring El, Val and C who live as master, mistress and slave; Bill, who became Diane after 37 years of marriage to Anita . . and Mike, who at $6 \mathrm{ft} 9 \mathrm{in}$ is almost two feet taller than his wife Ginny. 
These 'light-hearted', low-budget 'reality' shows open up a space for the representation of minoritized sexual cultures, though what their effects might be has yet to receive sustained academic scrutiny.

However, not all documentaries are always as light at these. In previous years Channel Four in the UK has broadcast a number of 'serious' portrayals of SM, including Madam Cyn's Home Movies, Me and My Slaves, and Fetishes, the latter directed by well-known documentary maker Nick Broomfield. Although these aim to be less sensationalist and voyeuristic than some of their low-budget counterparts, their supposed realism does not necessarily mean more balanced depictions. What is often found instead in these more 'high-brow' reports is a very blatant attempt by the producers to coax and coerce people into telling their sexual stories (Plummer, 1995). Fetishes is a clear example of this. Broomfield visits a dominatrix parlour in New York where he asks a number of questions such as 'so tell me about your upbringing' or 'does the fact you're a dominatrix affect your ability to have successful relationships with men?' While such films may well be made with a genuine interest by the producers to try and understand people's sexual behaviour, they still frame this understanding in familiar ways, focusing on psychological stories to help 'explain' SM practices. The Broomfield documentary attempts to give viewers a realistic account of the reasons behind SM in the hope that this will lead them to understand and tolerate such practices and lifestyles. Disturbed childhood experiences and unhappy previous relationships are unearthed in order to explain (excuse) how subjects came to be dominant or submissive. The psychologization of SM in these narratives is arguably more harmful than comedic representations, since it emphasizes the abnormality of sadomasochists. Would a documentary about heteromonogamous relationships feel the need to delve into the participants' childhoods? The very fact that SM is an object of study marks it as 'other'.

\section{The paradox of visibility}

Unsurprisingly the 'SM community' often feels some sense of resentment towards sensationalist media portrayals. As Califia and Sweeney (1996: xiv) write:

While it's nice to have people admire our clothes and to hear jokes about handcuffs during prime time these media references too often include damaging and dangerous stereotypes about us. When latex, leather, and metallic accessories are taken out of context, we get ripped off so the viewers at home can be titillated.

Queer politics has often assumed that increased publicity automatically leads to increased acceptance, that to make a change to the 'heteronormative' world order we need to take to the streets, to make our sexual 
practices visible (Bristow and Wilson, 1993). However, this equation is often overly simplistic (Hubbard, 2001); with increased visibility comes the risk of increased hostility too (Skeggs, 1999). Likewise, Weiss has demonstrated that 'there is no easy correlation between increased visibility . . . and activist goals' (2006: 119), drawing upon the Foucauldian concept of 'compulsory visibility', that in discipline, it is the subjects who have to be seen. Their visibility assures the hold of the power that is exercised over them' (Foucault, 1979: 187).

Weiss is quite right to point out the dangers of visibility and to draw attention to how disciplinary regimes are built upon the naming and hence constraining of subjects. However, I cannot help but feel that the only other option, 'invisibility', is now an impossibility. Visibility may lead to naming and constraining, but it also allows new things to be seeable and sayable, opening up space for counternarratives (Cooper, 1995). Historically it was not, of course, a case that minoritized sexual cultures actively chose to come into the public light, and SM was first propelled into the public realm through psychiatric discourse of the late 1880s. Yet today the fact is that SM is becoming an increasingly public story, so to remain silent is not an option. Sadomasochists have no choice but to step into the public sphere, to tell their own sexual stories, to speak back to the dominant pathologizing discourses. Without this there is little hope for social change, and sadomasochists will continue to be at the mercy of the psychiatric establishments, governmental policy, and judicial law.

I am not claiming that the mainstreaming of alternative sexualities is unproblematic; however, we must be able to reach a position that understands both the dangers and the possibilities that increased visibility can offer. Here, I feel we can learn important lessons from the increased visibility of gay and lesbian cultures. One of the most frequently expressed dangers of increased visibility here is its link to increased normalization, or 'homonormativity' (Duggan, 2002). We must be constantly aware that there is a very real danger of a parallel 'SM-normativity', in which certain (capitalist and consumerized) conceptions of SM become the norm. Already the mainstreaming of SM has led to a heteropatriarchal version of SM becoming dominant. With increased visibility there is also a danger we can begin to mistake the representation of SM for SM itself - that this is how it should and always will be. What is therefore needed is a space in which to make public a number of continuously contrasting and conflicting SM stories.

Constructive and diverse representations already exist within the spaces of SM, of course. Diverse depictions can be found in specialist magazines, literature, and (some forms of) SM pornography. However, it is unlikely that anyone from outside the scene will encounter such representations they exist as a kind of subcultural media (Thornton, 1995). Yet the main 
problem with a specialist market is that it remains just that. These marginalized forms of representation will do little to challenge the status quo as they are effectively 'preaching to the perverted'. What is needed is some form of media where subcultural representations can cross over into the mainstream. However, attempting to find a public stage to broadcast such representations proves a difficult task. Without any publicity, minoritized sexual cultures cannot challenge and change mainstream stereotypes. Therefore, how can they get positive public media representations on their own terms? I do not doubt that those who agree to go on documentaries about 'unusual' sexual practices have just this outcome in mind. They enter into these shows with the best intentions to put across their story (Gamson, 1998). Yet, in reality they often find themselves at the mercy of the production team, with finished shows edited to give the viewers the sensationalist story they want (Giles, 2002). Public visibility therefore continues to be a central dilemma for marginalized sexualities.

\section{New media, new representations?}

The important question we must therefore ask is: where can minoritized sexual cultures find a space where they can broadcast their own visual representations, on their own terms? Can we imagine a place in which alternative sexualities can produce images that are simultaneously outside and within reach of the mainstream? Which spaces allow for counternarratives that may challenge dominant stereotypes? Cyberspace may potentially provide such a space. At the time of Plummer's Telling Sexual Stories (1995), the use of the internet for broadcasting sexual representations was still in its infancy. However, he argued that it would increasingly be 'the mechanisms through which the story is told [that] will matter' (1995: 23). The growth in internet access has meant that the modes for transmitting sexual representations have changed. Here I wish to explore the possibilities the internet can offer for minoritized sexual groups; highlighting how cyberspace could offer the freedom to contest mainstream stereotypes. The internet provides a space for people to publicly broadcast sexual stories and images that would have previously only had the chance to exist either in private or in marginalized niches.

When examining media representations of sexuality it is crucial to pay attention to who has control over broadcasting. Previously, commercial sexual stories were often inseparable from the market, and, as Plummer notes, a story without an audience is unthinkable: for a story to be broadcast it would need to have sufficient predicted ratings to make it financially viable. ${ }^{9}$ Commercial representations therefore will often 'play it safe', as they are made to appeal to a mass audience. Hence existing mainstream images often replicate wider power structures, being both heteronormative 
and patriarchal: it is not in the interest of media producers and regulators to challenge the existing status quo, unless that challenge has sufficient audience appeal. However, personal internet stories and images do not need an audience to be broadcast; they can survive without a market as they are not produced for financial gain. ${ }^{10}$ Recent debates about 'Web 2.0' and about the rise of 'social networking' sites and practices focus on the ways that the internet is currently 'opening out' as a space for new media production and consumption practices (Bell, in press). In cyberspace, potentially everyone can be the authors of their own sexual stories and images. The internet therefore allows the margins to have a voice, rather than media conglomerates deciding which stories and what forms of representation are allowed public visibility.

The importance of the internet for queer subjects has been widely documented (International Journal of Sexuality and Gender Studies, 2002). However, much work has focused upon community and identity and has tended to neglect the more embodied aspects to sexuality, such as the production and consumption of pornography. It is crucial that this pornographic function is not overlooked, as it is a dimension to SM sexuality that is almost entirely missing from mainstream representations. As Langdridge highlights, 'while there has undoubtedly been a proliferation of SM stories, these stories ... . are inevitably radically de-sexualized' (2006: 374). Although society seems more than happy to consume the iconography and paraphernalia of SM, the actual sex acts are often seen as unacceptable. ${ }^{11}$ Perhaps because pornography provides a very different kind of sexual story. Pornography does not attempt to explain why or how the actors came to experience sex like this, it simply just is: a vivid representation of fucking for fucking's sake. The visual representation of sex acts reminds us that sexuality is a doing rather than a being. Maybe this is why porn is seen as so dangerous; it makes no attempts to explain or excuse itself, and therefore does not fit into the conventional methods of telling sexual stories. This is why, however, certain types of porn must be seen as an increasingly important tool for sexually marginalized groups. As Califia (1994: 103) states:

It sends out the messages of comfort and rebellion. It says: Lust is not evil. The body is not hateful. Physical pleasure is a joyful thing and should not be hidden or denied ... There are other people who think about and do the things you dream about. Freedom is possible. There is choice.

Internet pornography offers possibilities very distinct from mainstream commercial pornography; I would therefore dispute MacKinnon's claim that 'pornography in cyberspace is pornography in society, just broader, deeper, worse, and more of it' (1995: 1959). Although the vast majority of online pornography is undoubtedly sexist and heteronormative, there 
is also the possibility for marginalized sexual cultures to produce their own pornography. The increase in internet access and home-media means users are no longer necessarily restricted by lack of economic capital. ${ }^{12}$ In amateur pornography, people can be in control of the production, setting and acts; it therefore has possible democratizing potential (Kibby and Costello, 2001; Slater, 1998). We must be constantly aware that not all pornography reinforces the status quo. For example, SM pornography has traditionally been seen as antithetical to feminism (Jeffreys, 2003; Linden et al., 1982). However, the parameters of the anti-pornography debate have now shifted due to changing media forms. With new advances in technology we are now in the position where women can now be both the producers and consumers of their own consensual SM pornography. Jane Juffer (1998: 64) states that 'the computer does indeed have considerable potential for expanding women's sexual mobility'. Crucially, the internet offers a distinctively new space for women to explore sexual desires anonymously, without the stigma of entering the traditionally masculine spaces of pornography consumption (such as the sex shop or the porn cinema). The internet blurs the boundaries between public and private, and offers ease of access. Certain parts of the web open up an anonymous, private space for people to explore their sexual fantasies without fear of shame or reproach from wider society. Therefore, one of the vital functions the internet provides for minoritized sexualities is the wide range of pornography it offers.

In presenting the internet as a place where people can create their own sexual stories I do not wish to give the impression that I am arguing it provides space for a 'real' or 'authentic' SM story. Rather, cyberspace allows us to dispute any claims of a monolithic SM culture - sadomasochists do not form a unified identity or community. The internet also offers a space for those who are marginalized within marginalized groups, presenting us with a myriad sexual stories and images. It permits a wider range of sexual practices to be represented, and allows users a chance to challenge and test existing boundaries. In this sense, cyberspace can be considered a truly 'queer' space. The internet therefore does not offer a space to represent the SM story but a proliferation of contradictory and often conflicting stories. The internet is therefore a key site to contest dominant SM-normative representations.

Of course, this is not to claim that the visual representation of SM in cyberspace has any authority. Providing people a space to broadcast their own images does not mean that these representations will be given credibility, and such representations may still be contained and constrained by pre-existing dominant discourses. In fact, current popular narratives surrounding internet porn, which demonize users as addicts or geeks, also potentially limits the reach and impact of online porn. 
Although the internet has led to an even greater proliferation of personal sexual narratives, these still co-exist with older (and new) dominant narratives. Those dominant discourses will often attempt to silence counterdiscourses, moreover, bringing censorship to cyberspace.

\section{Censoring cyberspace}

Despite the mainstreaming of some forms of SM, there are still attempts to exclude certain images. The current UK government is attempting to limit the consumption of images of certain sadomasochistic and other 'extreme' sexual activities. In 2005 the Home Office held its Consultation on the Possession of Extreme Pornographic Material. At present, the government has the authority to restrict 'extreme' pornography websites based in the UK, but has no control over websites hosted in other countries. To close this 'loophole', it is proposed that the consumers of extreme pornography are prosecuted, rather than the producers (with a place on the sex offenders register and up to three years' imprisonment). The private consumption of 'extreme' pornographic images is seen as a matter of public concern. The government makes no attempt to differentiate between acts of non-consensual violence and consensual sadomasochistic sex, stating that it intends to regulate 'material which either is genuinely violent or conveys a realistic impression of fear, violence and harm' (Home Office, 2006: 6, my emphasis). ${ }^{13}$ It is difficult for me to go into any real depth about what sort of material will be covered by this legislation, as the consultation itself is worryingly but symptomatically vague, stating that 'It is not possible in a public document like this to give a great deal of graphic detail or description of the material in question' (Home Office, 2005: 5).

Opposition to this legislation argues that legitimate consensual sexual practices and representations will fall under the new laws. The government however, specifically states that 'mainstream' images of SM will not be covered by the legislation. Yet they fail to comprehend that SM incorporates much more than what we see in popular pornonormative representations. As Beckmann notes, the rising public acceptance of the label "kinky sex" means that "This label ... still excludes constructed "Others" who are designated as practicing "real perversion"' (Beckmann, 2001: 69). Despite the government thinking it understands SM, it has mistaken representation for reality.

This legislation presents a very negative representation of people in the SM scene who fall outside these conventional and containable SM stereotypes. The government alleges that representations of certain forms of consensual sex are so 'aberrant' they must be subject to legal prosecution. The idea that some types of SM pornography should be censored to 
protect people from 'corruption' denies sadomasochists the right to be seen as a valid sexual culture: in condemning the representation you condemn the reality. The legislation implies that those who view extreme images are potentially pathological and capable of murder: the laws are depicted as being there to protect people from themselves and from each other.

A crucial component of the legislation is its explicit regulation of 'extreme' images, defined as photographic and/or video materials. There is something particularly dangerous about the visual implied here: the written word is evidently less capable of producing harm or depravity in readers. The legislation thus repeats the contested assumptions about the immediacy and potency of visual realism, echoing earlier debates about the effects of cinematic violence (Barker and Petley, 1997). It also taps into the more recent moral panic about negative effects of internet use. In terms of the state regulation of SM, in fact, this emphasis on visual representation (as 'evidence') has precedence in the Regina v. Brown case (1993), when a group of SM practitioners was arrested and tried for giving and receiving consensual harm, the case underpinned by the group's private videos. This case, resulting from the police's infamous Operation Spanner, is also noteworthy here for its role in politicizing SM, helping to create a shared sense of oppositional unity among practitioners visibilized, for example, in 'SM Pride' rallies. The current legislation has to be contextualized, therefore, in terms of this longer-running demonization of SM, the consequent politicization of SM, and the troubled relationship between representation and regulation.

What implications does the censoring of these sexual images have for our wider social sexual imaginaries? Only 'mild' forms of SM are tolerated whereas anything more 'extreme' is still far from being accepted; we are not yet living in a society where one could witness pony play in our public parks, or read an article on 'How to Asphyxiate Your Partner Safely' in women's magazines. What is tolerated publicly is SM as an extension to vanilla heterosex, rather than a radical and oppositional alternative. Anything more 'extreme' is still considered a dangerous perversion. Freud defines perversion as a sexual activity that extends 'in an anatomical sense, beyond the regions of the body that are designed for sexual union' (1991 [1905]: 62). It is interesting to note that some of the images the government wishes to ban are striking examples of moving sex away from exclusive focus on the genitals to the eroticization of other parts of the body and to objects (e.g. breath play, electrical play). ${ }^{14}$ In making the viewing of 'extreme' pornography illegal, the government is effectively reinforcing the idea that genital sex is still the bedrock of contemporary human sexuality. ${ }^{15}$ 


\section{Representations and rights}

It is important in this debate that the lived experience of the consumers and producers of these representations are not overlooked. When discussing internet representation it is no longer just a matter of what implications these images will have on wider society, it also becomes a far more personal and embodied matter. The very production and consumption of these images can contribute to a person's sexual development and lived experience. New social media are argued to be flattening old distinctions between media producers and consumers, changing the entire media landscape. Yet many arguments used for censoring of internet pornography fail to take into account the changing context of pornography production. With the increase in amateur production, defending internet pornography is not just about defending commercial free speech, but also about defending the right to private self-expression. These laws will therefore have drastic implications upon the sadomasochists' rights to sexual citizenship. The legislation does not just restrict the consumption of images online, it covers any visual image of 'extreme sexual violence'. Therefore, selfproduced images of friends and partners that could have been made and consumed in the privacy of one's own home will also be made illegal.

The internet transgresses the boundaries of public and private, and this partly accounts for government concern. Sexual subcultures that previously existed 'over there' are now in such close proximity that they are only a click away. The virtual closeness of 'sexual others' may be disconcerting for some, and I do not wish to deny that some people do find these images distressing (much in the same way that people do not wish to see depictions of any violent act). ${ }^{16}$ The important issue is: what do we do when our intimate visions infringe upon others' sexual imaginaries and development? Should all sexual images be freely broadcast, or do we need some form of control? How do we respect the rights of people who find extreme SM offensive, whilst concurrently allowing those who find pleasure in this material the right to produce and consume?

Against current narratives of ubiquity, we might argue that the internet is far less pervasive than other forms of media communication. ${ }^{17}$ The proliferation of 'dangerous' sexual images on the internet is often over exaggerated, and contrary to popular belief, pornography does not flood our screens whenever we go online. Extreme pornography is consumed privately and by choice via the internet. As Cornell (1995: 149) states, 'we should distinguish between an offence that one can escape from and an offence that is forced on one'. She therefore proposes a form of zoning that keeps pornographic images out of view from those who do not wish to see, yet simultaneously instantly available to those who do. The internet offers such a space: a wide range of pornography is available if we actively 
search for it, however we can simultaneously choose not to view such images. It is in this light that any attempt to restrict people's use of the internet is unjust.

When attempting to achieve 'public decency' we must be constantly aware of the need to protect the private rights of minoritized sexualities. Stychin (1995) has warned of the dangers of adopting a notion of universal sexual rights, and any move towards regulating pornography must be approached with great caution. Here he is not suggesting we abandon rights and subjectivity in their entirety, but that we must pay particular attention to the history and experience of a subject position. Therefore SM pornography becomes inseparable from its wider history of oppression; it becomes political as well as sexual speech. One must not deny the fact that for some people exploration of 'extreme' pornography may be crucial to their sexual imaginary, and unless images are nonconsensually produced then the government should play no role in dictating what people should or should not view. ${ }^{18}$ For as Cornell states, only then will we 'be able to arrive at a mode of zoning that does not carry within it another view of whose imaginary should reign' (1995: 152).

Ultimately this legislation sets a dangerous precedent by restricting our freedom to view diverse sexual images. One of the government consultation questions asks:

In the absence of conclusive research results as to its possible negative effects, do you think that there is some pornographic material which is so degrading, violent or aberrant that it should not be tolerated? (Home Office, 2005: 10, my emphasis)

The fact that a law can be passed without any evidence suggests this legislation is defended solely on 'moral' grounds. Although the legislation may not have an effect on many people, its future implications could be further reaching for all those whose sexual tastes and practices fall outside the remit of 'normal' sexuality. We will be left at the mercy of whatever the government at the time decides is 'aberrant' and therefore 'should not be tolerated'. Although censorship may be introduced with the best intentions, it still remains to be proved that such laws can be implemented consistently and justly.

Through the 'extreme' pornography legislation, the government is attempting to harness the potentially democratic nature of cyberspace, and also reinforcing the supposed 'sexual otherness' of SM. Restraining people's rights to view sexual images denies them the chance to explore their sexual desires. Cyberspace offers us a vast variety of sexual images, it is a space where we can debate and contest what sexuality means and how it differs for each and every individual. These laws will foreclose any future attempts to explore the true extent and diversity of sexual desire, leaving 
us only with the 'mainstream' - a very rigid and narrow conception of human sexuality.

\section{Notes}

1. See showbiz.sky.com (2006).

2. See Bell 2007 who discusses 'pornonormativity' in terms of the ways that the images and narratives of porn provide their viewers with particular sexual scripts and expectations about sex.

3. I do not want to deny that many people within the SM scene derive pleasure or affirmation from these representations. All too often academics speak about representations as if they have the authority to speak for the entire SM world, failing to even understand or ask what SM practitioners themselves think (although see Barrett 2007).

4. See neverinneutral.com (n.d.).

5. Thanks to my anonymous referee for making this observation.

6. See encams.org (2008).

7. See wilsonsalmanac.com (n.d.).

8. In the same way, the death of British actor John Inman on 8 March 2007 led to considerable debate about the 'effects' of his most famous role, the camp sales assistant, Mr Humphries, in the UK sitcom Are You Being Served?

9. Where state-owned channels sometimes have a remit for 'minority broadcasting' - as did Channel 4 when it was founded - this has never extended to sexual minorities beyond lesbians and gay men.

10. This is not of course to claim that these technological advances are a distinctly new phenomenon, for example, in the mid-1980s the widespread use of the VCR saw dramatic changes in the types of pornography available and changes to patterns of production, distribution and consumption. However, although amateur porn existed prior to the internet, the sheer volume and ease of access to both production and consumption is now greater than ever before (see O'Toole, 1999, for a comprehensive account of the complex history of technology and pornography).

11. Mainstream porn only depicts a narrow range of SM practices, mostly involving the milder forms of bondage and domination.

12. Although obviously the unequal geographies of internet access must also be addressed (Warf, 2001).

13. The class-based implications of this legislation are also unmistakable - high art $v$. mass culture (porn). The government reassures that certificate 18 films will not be covered by this legislation, even when the acts of violence and sex may be far more graphic and realistic than anything one could find on the internet. High-brow films can of course blur sex and violence - the assumed viewers can put these acts into context, and differentiate between fantasy and reality. The viewers of internet pornography however are granted no such leeway.

14. That is, 'acts that appear to be life threatening' (Home Office, 2006: 6).

15. The most recent version of the proposed legislation now reads 'serious injury to a person's anus, breasts or genitals' (House of Commons, 2007: 
$45)$. The government are unable to even imagine a sexual act that moves beyond the traditional erogenous zones.

16. Images of real-life non-sexual torture are not touched upon in this legislation.

17. See the US 1996 Communications Decency Act (CDA) which attempted to limit minors' access to internet pornography. The Supreme Court overturned the act stating that the internet did not qualify for the same standard applied to broadcasting 'on the grounds that cyberspace is not as “invasive" as radio or television' (Warf, 2001: 9).

18. The internet's lack of regulation and its anonymity mean it is difficult to monitor whether an image is an actual act of violence. However, this legislation is not proposing any sort of punishment for those who produce non-consensual pornography.

\section{References}

Attwood, F. (2006) 'Sexed Up: Theorizing the Sexualization of Culture', Sexualities 2(9): 77-94.

Barker, M. and Petley, J. (1997) Ill Effects: The Media/Violence Debate. London: Routledge.

Barrett, J. (2007) “"You've Made Mistress Very, Very Angry” Displeasure and Pleasure in Media Representations of BDSM', Particip@tions 4(1), URL (accessed November 2008): http://www.participations.org/Volume\%204/ Issue\%201/4_01_barrett.htm

Beckmann, A. (2001) 'Deconstructing Myths: The Social Construction of "Sadomasochism" Versus "Subjugated Knowledges" of Practitioners of Consensual "SM"', Journal of Criminal Justice and Popular Culture, 8(2): 66-95.

Bell, D. (2007) 'Bodies, Technologies, Spaces: On "Dogging”', Sexualities 9(4): 387-407.

Bell, D. (in press) 'On the Net: The World Wide Web', in G. Creeber and Royston Martin (eds) Digital Culture: Understanding New Media. London: BFI.

Binnie, J. (1994) 'The Twilight World of the Sadomasochist', in S. Whittle (ed.) The Margins of the City: Gay Men's Urban Lives, pp. 157-71. Aldershot: Ashgate.

Bristow, J. and Wilson, A. (eds) (1993) Activating Theory: Lesbian, Gay, Bisexual Politics. London: Lawrence \& Wishart.

Califia, P. (1994) Public Sex: The Culture of Radical Sex. Pittsburgh: Cleiss.

Califia, P. and Sweeney, R. (eds) (1996) The Second Coming: A Leatherdyke Reader. Los Angeles: Alyson.

Cooper, D. (1995) Power in Struggle: Feminism, Sexuality and the State. Buckingham: Open University Press.

Cornell, D. (1995) The Imaginary Domain. London: Routledge.

Duggan, L. (2002) 'The New Homonormativity: The Sexual Politics of Neoliberalism', in R. Castronovo and D. Nelson (eds) Materializing Democracy: Toward a Revitalized Cultural Politics, pp. 175-94. Durham, NC: Duke University Press. 
encams.org (2008) URL (accessed December 2008): www.encams.org/general/ advert.asp

Falk, G. and Weinberg, T. (1983) 'Sadomasochism and Popular Western Culture', in T. Weinberg and G.W. Levi Kamel (eds) $S$ and M: Studies in Sadomasochism, pp. 137-44. Prometheus: New York.

Foucault, M. (1979) Discipline and Punish: The Birth of the Prison. London: Penguin.

Freud, S. (1991 [1905]) On Sexuality: Three Essays on the Theory of Sexuality and Other Works. Harmondsworth: Penguin.

Gamson, J. (1998) Freaks Talkback: Tabloid Talk Shows and Sexual Noncomformity. Chicago, IL: University of Chicago Press.

Giles, D. (2002) 'Keeping the Public in their Place: Audience Participation in Lifestyle Television Programming', Discourse and Society 13(5): 603-28.

Hall, S. (1980) 'Encoding/Decoding', in S. Hall, D. Hobson, A. Lowe and P. Willis (eds), Culture, Media, Language, pp. 128-38. London: Hutchinson.

Home Office (2005) Consultation: On the Possession of Extreme Pornographic Material. London: Home Office Communication Directorate.

Home Office (2006) Consultation: On the Possession of Extreme Pornographic Material. Summary of Responses and Next Steps. London: Home Office Communication Directorate.

House of Commons (2007) Criminal Justice and Immigration Bill. London: Her Majesty's Stationery Office.

Hubbard, P. (2001) 'Sex Zones: Intimacy, Citizenship, and Public Space', Sexualities 4(1): 51-71.

Hunt, L. (1998) British Low Culture: From Safari Suits to Sexploitation. London: Routledge.

International Journal of Sexuality and Gender Studies (2002) 'Queer Webs: Representations of LGBT People and Communities on the World Wide Web', $7(2-3)$.

Jeffreys, S. (2003) Unpacking Queer Politics: A Lesbian Feminist Perspective. Cambridge: Polity.

Juffer, J. (1998) At Home with Pornography, Women, Sex, and Everyday Life. New York and London: New York University Press

Kibby, M. and Costello, B. (2001) 'Between the Image and the Act: Interactive Sex Entertainment on the Internet', Sexualities 4(3): 353-69.

Langdridge, D. (2006) 'Voices from the Margins: Sadomasochism and Sexual Citizenship', Citizenship Studies 10(4): 373-89.

Langdridge, D. and Butt, T. (2004) 'A Hermeneutic Phenomenological Investigation of the Construction of Sadomasochistic Identities', Sexualities 7(1): 31-53.

Linden, R. R., Pagano, D. R., Russell, D. E. H. and Star, S. L. (1982) Against Sadomasochism. Palo Alto, CA: Frog in the Well.

MacKinnon, C. (1995) 'Vindication and Resistance: A Response to the Carnegie Mellon Study of Pornography in Cyberspace', Georgetown Law Journal 83(5): 1959-1968.

McNair, B. (2002) Striptease Culture: Sex, Media and the Democratization of Desire. London: Routledge. 
neverinneutral.com (n.d.) URL (accessed December 2008): www.neverinneutral.com/dominatrix/

O’Toole, L. (1999) Pornocopia: Porn, Sex, Technology and Desire. London: Serpent's Tail.

Plummer, K. (1995) Telling Sexual Stories: Power, Change and Social Worlds. London: Routledge.

Regina v. Brown, (1993) 2 WLR 556; (1992) 2 AII ER 75 (The Spanner case).

Rubin, G. (1992 [1984]) 'Thinking Sex: Notes for a Radical Theory of the Politics of Sexuality', in C. Vance (ed.) Pleasure and Danger, Exploring Female Sexuality, pp. 267-319. London: Pandora Press

Shortes, C. (1998) "“Cleaning up a Sewer": The Containment of S/M Pornography', Journal of Popular Film and Television 26(2): 72-9.

showbiz.sky.com (2006) '10 Sexiest Film Scenes Ever. . .' 13 March 2006, URL (accessed December 2008): showbiz.sky.com/10-Sexiest-Film-Scenes-Ever

Skeggs, B. (1999) 'Matter Out of Place: Visibility and Sexualities in Leisure Spaces', Leisure Studies 18(3): 213-32.

Slater, D. (1998) 'Trading Sexpics on IRC: Embodiment and Authenticity on the Internet', Body o Society 4(4): 91-117.

Storr, M. (2003) Latex and Lingerie: Shopping for Pleasure at Ann Summers. Oxford: Berg.

Stychin, C. (1995) Law's Desire: Sexuality and the Limits of Justice. London and New York: Routledge

Taylor, G. and Ussher, J. (2001) 'Making Sense of S\&M: A Discourse Analytic Account', Sexualities 4(3): 293-314.

Thornton, S. (1995) Club Cultures: Music, Media and Subcultural Capital. Cambridge: Polity.

Warf, B. (2001) 'Segueways into Cyberspace: Multiple Geographies of the Digital Divide', Environment and Planning B: Planning and Design, 28(1): 3-19

Weinberg, T. and Magill, M. (1995) 'Sadomasochistic Themes in Mainstream Culture', in T. Weinberg (ed.) SerM: Studies in Dominance and Submission, pp. 223-30. New York: Prometheus.

Weiss, M. (2006) 'Mainstreaming Kink: The Politics of BDSM Representation in U.S Popular Media', Journal of Homosexuality 50(2/3): 103-32.

wilsonsalmanac.com (n.d.) URL (accessed December 2008):

www.wilsonsalmanac.com/voodoo.html

\section{Biographical Note}

Eleanor Wilkinson is a Research Cluster Associate and PhD student in Human Geography at the University of Leeds. Her PhD is entitled 'Spaces of Love', and aims to map love onto a variety of spatial scales, highlighting how our intimate lives are not solely a personal matter but have wider cultural, political and economic consequences. Her current research interests include polyamory, radical celibacy, countercultural queer politics and autonomous spaces. Forthcoming publications include 'What's Queer About Non-monogamy Now?' in Barker and Langdrige (eds) Understanding Non-monogamies (Routledge, in press). Address: School of Geography, University of Leeds, Leeds, LS2 9JT, UK. [email: e.k.wilkinson@leeds.ac.uk] 